\title{
The Impact of Different Tannin to Anthocyanin Ratios and of Oxygen on the Phenolic Polymerisation Over Time in a Wine-like Solution
}

\author{
G. Garrido-Bañuelos ${ }^{1 \#}$, A. Buica ${ }^{1 *}$, E. Sharp ${ }^{1,2}$, A. de Villiers ${ }^{2}$, W. J. du Toit ${ }^{1}$ \\ (1) Department of Viticulture and Oenology, Stellenbosch University, Private Bag X1, Matieland 7062, South Africa. \\ (2) Department of Chemistry and Polymer Science, Stellenbosch University, Private Bag X1, Matieland 7062, South Africa.
}

Submitted for publication: February 2019

Accepted for publication: May 2019

Key words: Phenolic compounds; wine-like extract; oxygen; polymerisation; anthocyanin/tannin extracts; ageing

\begin{abstract}
Colour and phenolic stability during ageing are influenced by the levels of distinct classes of phenolics in young red wines. The ratios between different classes of phenolic compounds also determine the colour and phenolic development of red wines. The present study evaluated the impact of forced oxidation on different anthocyanin/tannin (A/T) extracts and its consequent effect on the colour and phenolic evolution over time. The results showed that higher contents of seed tannins could enhance phenolic polymer formation, especially in the presence of oxygen. The addition of oxygen seemed to favour certain polymerisation reactions between tannins, leading to higher concentrations of monomeric anthocyanins in solution. A slower oxygen consumption was also observed as the phenolic composition of the wine-like extract evolved over time.
\end{abstract}

\section{INTRODUCTION}

Red wine quality can be directly influenced by phenolic compounds. Colour and phenolic stability of red wine are parameters that are related to consumer acceptance of the product. Grape phenolics are the main source of these secondary metabolites, which are progressively extracted during alcoholic fermentation as the ethanol concentration increases (Peyrot Des Gachons \& Kennedy, 2003; GonzálezManzano et al., 2004; Ribéreau-Gayon et al., 2006). Grape anthocyanins and condensed tannins (proanthocyanidins) are the most important groups of phenolic compounds in red wines due to their involvement in determining the colour and sensory properties (Cheynier et al., 2006; He et al., 2012a, 2012b). Anthocyanins are normally exclusively extracted from the grape skins, whereas condensed tannins also originate from the grape skins, stems and seeds (Meyer \& Hernandez, 1970; Pascual et al., 2016). Differences in the chemical structure, polymer length and \% galloylation of grape tannins can influence their extractability (GonzálezManzano et al., 2006), reactivity and thereby their final impact on the sensory properties of wines (Peleg et al., 1999). Grape tannins can be subdivided in two groups: procyanidins and prodelphinidins (Cheynier et al., 2006; Kennedy et al., 2006; Mattivi et al., 2009). Prodelphinidins are only found in grape skins, whilst procyanidins are extracted from grape skins and seeds and consist of units of $(+)$-catechin and its epimer, (-)-epicatechin (Souquet et al., 1996; Adams, 2006).
From crushing, anthocyanins and tannins are chemically modified and undergo continual evolution over time, leading to the formation of new and more stable compounds (PérezMagariño \& González-SanJosé, 2004; Monagas et al., 2006; He et al., 2012b; Arapitsas et al., 2014, 2016; Bimpilas et al., 2015). Skin tannins, together with anthocyanins, follow a sigmoidal extraction, reaching a plateau in the early stages of the alcoholic fermentation (Mattivi et al., 2009; Yacco et al., 2016). However, longer maceration periods are required to reach better extraction of seed phenols due to a necessary hydration phase of the grape seeds (Casassa, 2017), leading to different levels of anthocyanins (A) and total tannins (T). The initial $\mathrm{A} / \mathrm{T}$ ratio of wine must is thought to affect the subsequent polymerisation reactions in wine (Singleton \& Trousdale, 1992; Sparrow et al., 2015) and the interaction of phenolic compounds with other wine components (Bindon et al., 2010; Springer et al., 2016). Reactions such as polymerisation, condensation between tannins and anthocyanins, or the formation of complexes with proteins or polysaccharides depend on the different types of tannins and their concentrations in the wine.

Oxygen is involved in several of these reactions, such as phenolic polymerisation, which leads to the formation of more complex and stable phenolic compounds (Fulcrand et al., 1996; Atanasova et al., 2002). The oxidation of ethanol produces acetaldehyde, which enhances the formation of

\footnotetext{
*Corresponding author: E-mail address: abuica@sun.ac.za

\#Present address: Product Design and Perception, RISE Research Institutes of Sweden-Agrifood and Bioscience, Box 5401, S-402 29, Göteborg, Sweden. Acknowledgements: The authors would like to thank Winetech, Thrip and NRF for financial support
} 
ethyl-bridged composite phenols (Timberlake \& Bridle, 1977; Dallas et al., 1996; Saucier et al., 1997; Es-Safi et al., 1999; Waterhouse \& Laurie, 2006). At lower doses, the impact of oxygen can be beneficial, increasing colour stability and improving wine taste and structure (Waterhouse \& Laurie, 2006; Gambuti et al., 2013). However, the oxygen intake should be controlled to avoid excessive production of acetaldehyde and subsequent over-polymerisation and precipitation (Castellari, et al., 2000; Du Toit, et al., 2006a; Ribéreau-Gayon, et al., 2006). The ageing potential of a wine seems to be influenced by the nature of the tannins and the relative A/T ratios (Singleton \& Trousdale, 1992; Ribéreau-Gayon et al., 2006; Pascual et al., 2016; Picariello et al., 2017), but this needs further clarification. Two recent publications have evaluated the oxygen consumption of several oenological tannins in a model wine solution, showing how the different nature of the tannins (model wine solutions rich in ellagitannins, gallotannins, skin tannins or seed tannins) influence the oxygen consumption rates (Pascual et al., 2017; Vignault et al., 2018). However, the impact of a continuous oxygen exposure and how the new phenolic polymers formed during ageing react towards it still remains unknown.

There are many unknowns in the continuous evolution of wine phenols during ageing. Current analytical methods can only provide limited information on the different phenolic polymer structures. The impact of oxygen on wine phenols in general has been examined extensively (Castellari et al., 2000; Atanasova et al., 2002; Wirth et al., 2010; Arapitsas et al., 2012; McRae et al., 2015; Quaglieri et al., 2017). However, only two recent publications have evaluated the effect of oxygen on wines with different A/T ratios (Picariello et al., 2017; Carrascón et al., 2018). In the study from Picariello et al. (2017), the commercial tannins used may contain additional non-tannin compounds, thereby not only altering tannin concentrations but also those of other wine components and complicating interpretation of their findings (Versari et al., 2013). The present work aimed to investigate how oxygen affects phenolic polymerisation reactions at different $\mathrm{A} / \mathrm{T}$ extracts in a wine-like (WL) system. To our knowledge this is the first study that focuses on proanthocyanidin polymerisation reactions as a function of the combination of these two variables (oxygen and $\mathrm{A} / \mathrm{T}$ ratio). In addition, we also evaluate the different oxygen consumption patterns over time.

\section{MATERIALS AND METHODS}

\section{Wine-like extracts}

Shiraz grapes were harvested in 2015 from the Welgevallen experimental vineyard of the Department of Viticulture and Oenology at Stellenbosch University. The experimental design consisted of three different extracts, obtained by varying the amount of seeds used in the extraction and therefore the $\mathrm{A} / \mathrm{T}$ ratio. The three extracts were obtained from $240 \mathrm{~g}$ grape skin without any grape seeds added (SK), in a normal seed $(80 \mathrm{~g})$ to skin ratio (SKSD) and in the presence of four times the normal seed (320 g) to skin ratio (SK4SD) found in the Shiraz grapes of the study. All extractions were carried out for nine days at $25^{\circ} \mathrm{C}$ in $1 \mathrm{~L}$ hydroalcoholic solution ( $15 \%$ ethanol) at $\mathrm{pH} 3.4$ and containing $6.0 \mathrm{~g} / \mathrm{L}$ tartaric acid.
To avoid the possibility of spontaneous fermentation during sample storage, $20 \mathrm{mg} / \mathrm{L} \mathrm{NaN}_{3}$ (Sigma-Aldrich, St. Louis, MO, USA) was added to the extracts. All extractions were manually shaken three times per day. A single extraction was performed per extract. After nine days, the skins and seeds from their corresponding extract were removed and softly pressed by hand in the presence of $\mathrm{CO}_{2}$. The iron and copper concentrations were then adjusted to $5 \mathrm{mg} / \mathrm{L}$ and $0.3 \mathrm{mg} / \mathrm{L}$, respectively, by adding the requisite amounts of $\mathrm{FeSO}_{4} \cdot 7 \mathrm{H}_{2} \mathrm{O}$ and $\mathrm{CuSO}_{4} \cdot 5 \mathrm{H}_{2} \mathrm{O}$ (Sigma-Aldrich) according to Danilewicz (2007). The three final extracts (SK, SKSD, and SK4SD) were then centrifuged at $8000 \mathrm{rpm}(5 \mathrm{~min})$ to remove any residual grape skins.

The extracts were then divided into Control (C) and Oxygen treatments $(\mathrm{Ox})$, transferred to vials $(20 \mathrm{~mL}$ vials for $\mathrm{C}$ and $100 \mathrm{~mL}$ vials for $\mathrm{Ox}$ ) and sealed hermetically, with the use of crimp caps. Ox samples were exposed to a forced oxidation before being transferred to the vials. The Ox samples were vigorously shaken by hand in a 500 $\mathrm{mL}$ volumetric flask for 2 minutes, allowing air to enter every 10 seconds to reach oxygen saturation. On the other hand, $\mathrm{C}$ treatments were directly transferred into the vials (previously filled with nitrogen), while blowing $\mathrm{CO}_{2}$ into the vial. All vials were stored in the dark at $15^{\circ} \mathrm{C}$ until the required analysis after $3(3 \mathrm{M}), 6(6 \mathrm{M})$ and 9 months $(9 \mathrm{M})$ of storage. Once opened and analysed, $\mathrm{C}$ treatment vials were discarded, whereas in the case of Ox samples, $20 \mathrm{~mL}$ were drawn for the colour and phenolic analysis and the remainder of the extract was again saturated with oxygen before further storage. Glass beads were used to fill the headspace in the Ox vials at each of the sampling stages. In total, Ox samples were saturated with oxygen three times (at time $0-0 \mathrm{M}$, after $3 \mathrm{M}$ and $6 \mathrm{M}$ ). The oxygen introduced ranged between 6.8-7.6 $\mathrm{mg} / \mathrm{L}$ at time $0,7.1-7.6 \mathrm{mg} / \mathrm{L}$ after $3 \mathrm{M}$ and $8.5-$ $8.9 \mathrm{mg} / \mathrm{L}$ after $6 \mathrm{M}$.

\section{Oxygen measurement}

Oxygen spots (Pst3, PreSens, Regensburg, Germany) were placed in several vials (control and oxygen vials) to avoid invasive measurements and used to monitor the oxygen uptake rate (Coetzee et al., 2016). The oxygen consumption was monitored in $\mathrm{C}$ and $\mathrm{Ox}$ samples for the first 70-75 hours after oxygen addition. Vials were stored in the dark to avoid possible damage to the spots.

\section{Colour and phenolic measurements Spectrophotometric analysis}

The colour and phenolic composition were analysed at time $0 \mathrm{M}$ in each of the three extracts. In addition, these parameters were measured in $\mathrm{C}$ and $\mathrm{Ox}$ samples at $3 \mathrm{M}, 6 \mathrm{M}$ and $9 \mathrm{M}$ of storage. At each time point, three vials of each treatment were opened and analysed. The colour density (CD), total red pigments (TRP) and total phenols (TP) of the samples were measured by spectrophotometric analysis (Somers \& Evans, 1974; Boulton, 2001). TRP and TP were obtained from the absorbance units (AU) at $280 \mathrm{~nm}$ and $520 \mathrm{~nm}$ from wine-like samples diluted in $1 \mathrm{M} \mathrm{HCl}$. Tannin concentrations of the samples were then detemined by the methyl cellulose precipitation (MCP) method (Sarneckis et al., 2006) and the results are expressed (in catechin equivalents) in $\mathrm{mg} / \mathrm{L}$. 


\section{Reversed phase high performance liquid chromatography (RP-HPLC)-DAD analyses}

The analysis of individual and polymeric phenolic compounds were also performed at $0 \mathrm{M}$ and for all treatments after $3 \mathrm{M}, 6 \mathrm{M}$ and $9 \mathrm{M}$ of storage using RPHPLC according to Garrido-Bañuelos et al. (2019). WL samples were centrifuged for $5 \mathrm{~min}$ at $8000 \mathrm{rpm}$ and $20 \mu \mathrm{L}$ of the supernatant was injected. Calibrations were done for the following phenolic standards with additional compounds quantified as equivalents indicated in brackets: gallic acid, (+)-catechin ((-)-epicatechin, B1, polymeric phenols), caffeic acid (GRP, caftaric acid), p-coumaric acid, quercetin-3-glucoside (quercetin-3-glucuronide, quercetin-3-galactoside), quercetin, myricetin, kaempferol from Sigma-Aldrich Chemie (Steinheim, Germany), and malvidin-3-glucoside (delphinidin-, cyanidin-, malvidin-, peonidin-, petunidin- 3-glucosides, -3-acetyl-glucosides, -3-p-coumaryl-glucosides, polymeric pigments) from Extrasynthese (Lyon, France). The identification of the compounds was done based on retention times of standards and the UV-Vis spectra (acquired by injection of standards or from the literature). To simplify the large set of data, certain individual compounds were grouped, namely the sum of total hydroxycinnamic acids, total flavonols, the total glucosylated-anthocyanins, total acetylated-anthocyanins and total coumaroylated-anthocyanins.

\section{Statistical analysis}

All analyses were carried out using Statistica 13.2 (TIBCO Statistica software, Palo Alto, CA, USA). Significant differences were judged on a $5 \%$ significance level $(p \leq 0.05)$ with Fisher LSD Post Hoc tests. Principal Component Analysis (PCA) was performed with SIMCA 14.1 software (Sartorium Stedim Biotech - Malmö, Sweden).

\section{RESULTS AND DISCUSSION}

\section{Colour and phenolic extraction in the different extracts}

Based on previous trials, all extractions were performed for nine days in order to allow for a better extraction from the grape seeds. At $0 \mathrm{M}$ (after nine days of extraction) the colour density (CD) and the total red pigments (TRP) were similar between the three extracts. As expected, higher TP and tannin concentration were found in the SKSD and especially SK4SD samples prepared with more seeds, compared to SK (prepared with only skin tannins). Considering the individual phenolic compounds, especially gallic acid and catechin concentrations were significantly different between the different extracts at $0 \mathrm{M}$ (Table 1).

\section{Influence of a different phenolic extract on oxygen con- sumption}

The oxygen consumption $(\mathrm{mg} / \mathrm{L})$ was firstly monitored for the $\mathrm{C}$ and $\mathrm{Ox}$ samples at $0 \mathrm{M}$, and only for Ox samples in

TABLE 1

Colour and phenolic composition of the three extracts at $0 \mathrm{M}$.

\begin{tabular}{|c|c|c|c|}
\hline & SK & SKSD & SK4SD \\
\hline \multicolumn{4}{|l|}{ Spectrophotometric } \\
\hline 420 nm (AU) & 3.04 & 3.45 & 3.30 \\
\hline $520 \mathrm{~nm}(\mathrm{AU})$ & 6.75 & 7.48 & 6.76 \\
\hline $620 \mathrm{~nm}(\mathrm{AU})$ & 1.18 & 1.39 & 1.34 \\
\hline $\mathrm{CD}(\mathrm{AU})$ & 10.96 & 12.31 & 11.40 \\
\hline TRP (AU) & 24.02 & 26.23 & 24.01 \\
\hline TP (AU) & 32.37 & 39.86 & 48.99 \\
\hline Tannins (mg/L) & 450.99 & 587.86 & 1092.77 \\
\hline \multicolumn{4}{|l|}{$\underline{\operatorname{HPLC}(\mathrm{mg} / \mathrm{L})}$} \\
\hline Gallic acid & 2.67 & 31.92 & 86.13 \\
\hline Catechin & 8.60 & 59.76 & 154.14 \\
\hline B1 & 16.35 & 47.50 & 88.28 \\
\hline Polymeric phenols & 245.66 & 403.40 & 392.75 \\
\hline Total hydroxycinnamic acids & 4.82 & 7.07 & 7.78 \\
\hline Total flavonols & 67.24 & 85.09 & 75.15 \\
\hline Total glucosylated anthocyanins & 230.42 & 284.08 & 245.09 \\
\hline Total acetylated anthocyanins & 116.79 & 144.60 & 121.15 \\
\hline Total coumaroylated anthocyanins & 65.38 & 90.96 & 90.94 \\
\hline Polymeric pigments & 14.24 & 25.50 & 32.02 \\
\hline Total anthocyanins & 426.83 & 545.14 & 489.20 \\
\hline
\end{tabular}


the following oxygenations after $3 \mathrm{M}$ and $6 \mathrm{M}$ of storage. The oxygen consumption of the following oxidations was only monitored during the first three days (70-75 hours). As illustrated in Figure 1, the different extracts, which probably differ in concentration and chemical nature, clearly played a role as the oxygen consumption rates differed between the storage times and treatments. These differences in the oxygen depletion rates could possibly be explained by changes occurring in the phenolic profile and concentration of the extracts over time. Firstly, as shown in Figure $1 \mathrm{~A} 1$, there was a quick depletion of the low amount of oxygen present in $\mathrm{C}$ samples (probably due to a minimal oxygen intake during sample preparation). From Figure 1 A2, which illustrates the oxygen consumption in $\mathrm{Ox}$ vials at $0 \mathrm{M}$, minimal differences were found between the extracts. At $0 \mathrm{M}$, the higher phenolic levels, together with possible differences in the nature of the phenols, did not seem to influence oxygen consumption, differing from the findings of Pascual et al., (2017). In both cases, the dissolved oxygen in the different extracts was depleted after a few hours. On the other hand, the oxygen consumption rate varied over time, as the phenolic profiles of the extracts evolved. Oxygen consumption measured after $3 \mathrm{M}$ was generally slower compared to $0 \mathrm{M}$ (Figure $1 \mathrm{~A} 3$ ). Interestingly, after $3 \mathrm{M}$ the oxygen consumption was slower in the SK4SD samples. We consider that the initial excess of seed phenols may have had an influence on the formation rate of new polymeric forms involving oxidative reactions during the early stages of storage. This may have led to an extract composition with lower levels of compounds susceptible to oxidation after $3 \mathrm{M}$. Furthermore, oxygen consumption observed in Figure $1 \mathrm{~A} 4$ was even slower for all three extracts after $6 \mathrm{M}$, probably also as a consequence of a lower substrate availability to react with oxygen in the WL media.

\section{Colour and phenolic evolution of the final extracts}

Differences were observed in terms of the colour parameter and phenolic levels as determined spectrophotometrically at $0 \mathrm{M}$, as well as a function of storage time. Storage time played a particularly important role, as significant differences were also found in colour and the phenolic concentration between the different extracts over time. Whilst the extract was the most important factor in determining TP levels and, obviously, the tannin concentration, oxygen had a large influence on the colour parameter such as the TRP and CD, especially the absorbance at $420 \mathrm{~nm}$ for the latter. Furthermore, time was also a determining factor, especially for the TRP.

The evolution of the phenolic parameters determined spectrophotometrically as a function of time for the three extracts and $\mathrm{C}$ and $\mathrm{Ox}$ samples are shown in Figure 2. The cumulative effect of all the studied parameters drives a clear separation between the samples. In Figure $2 \mathrm{~A} 1$, it can be seen that the different extracts were separated along the PC1 axis (54.4\%). As previously mentioned, the TP and tannin concentration were mainly influenced by the respective extract composition. The scores plot and the corresponding loadings plot (Figure 2- A1 and B) showed a general higher
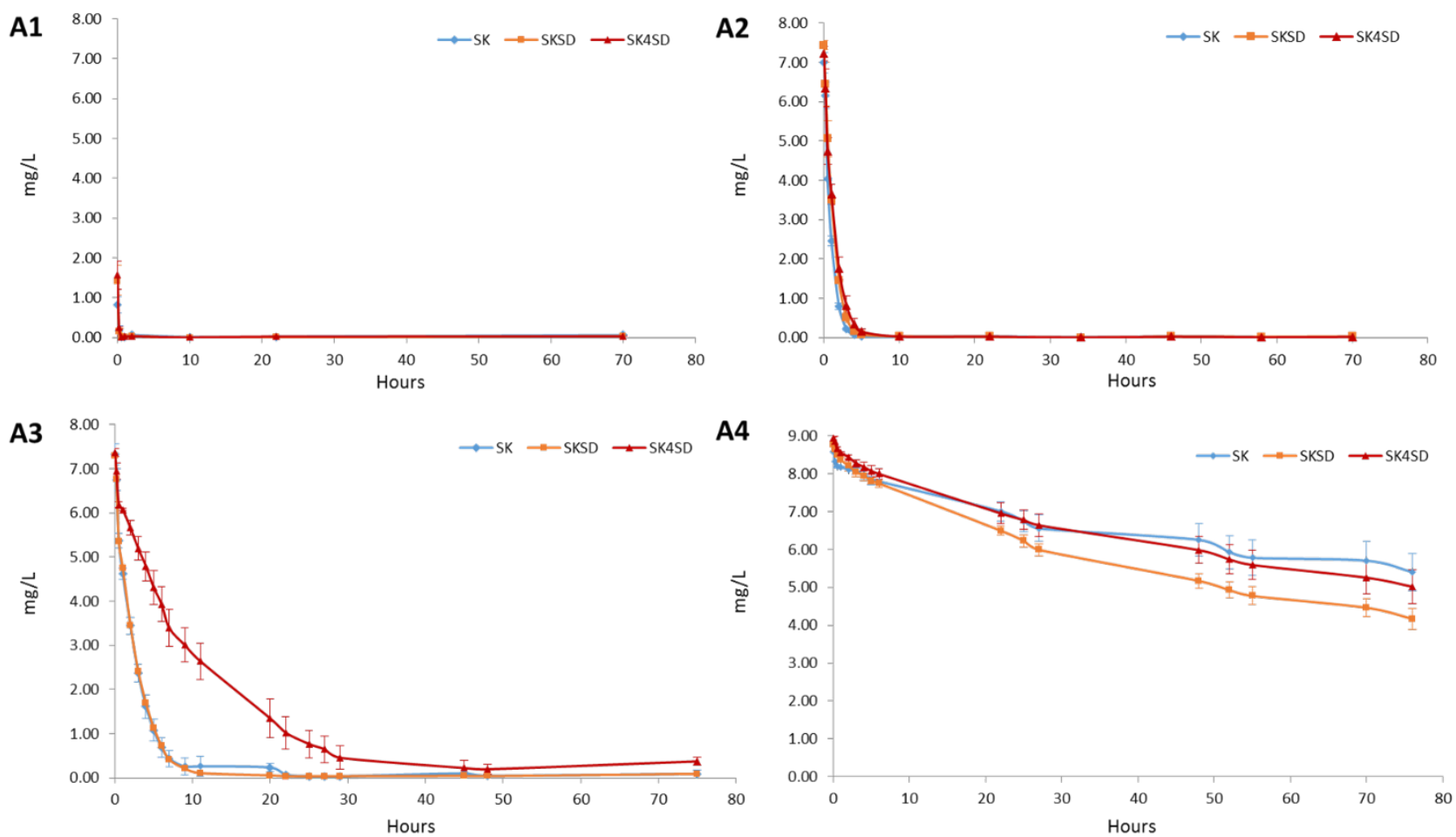

FIGURE 1

Oxygen consumption for the various treatments (SK, SKSD, and SK4SD). A1) oxygen consumption in C samples at 0 M. A2) oxygen consumption of Ox samples at $0 \mathrm{M}$. A3) oxygen consumption of Ox samples at $3 \mathrm{M}$. A4) oxygen consumption of Ox samples at $6 \mathrm{M}$. 

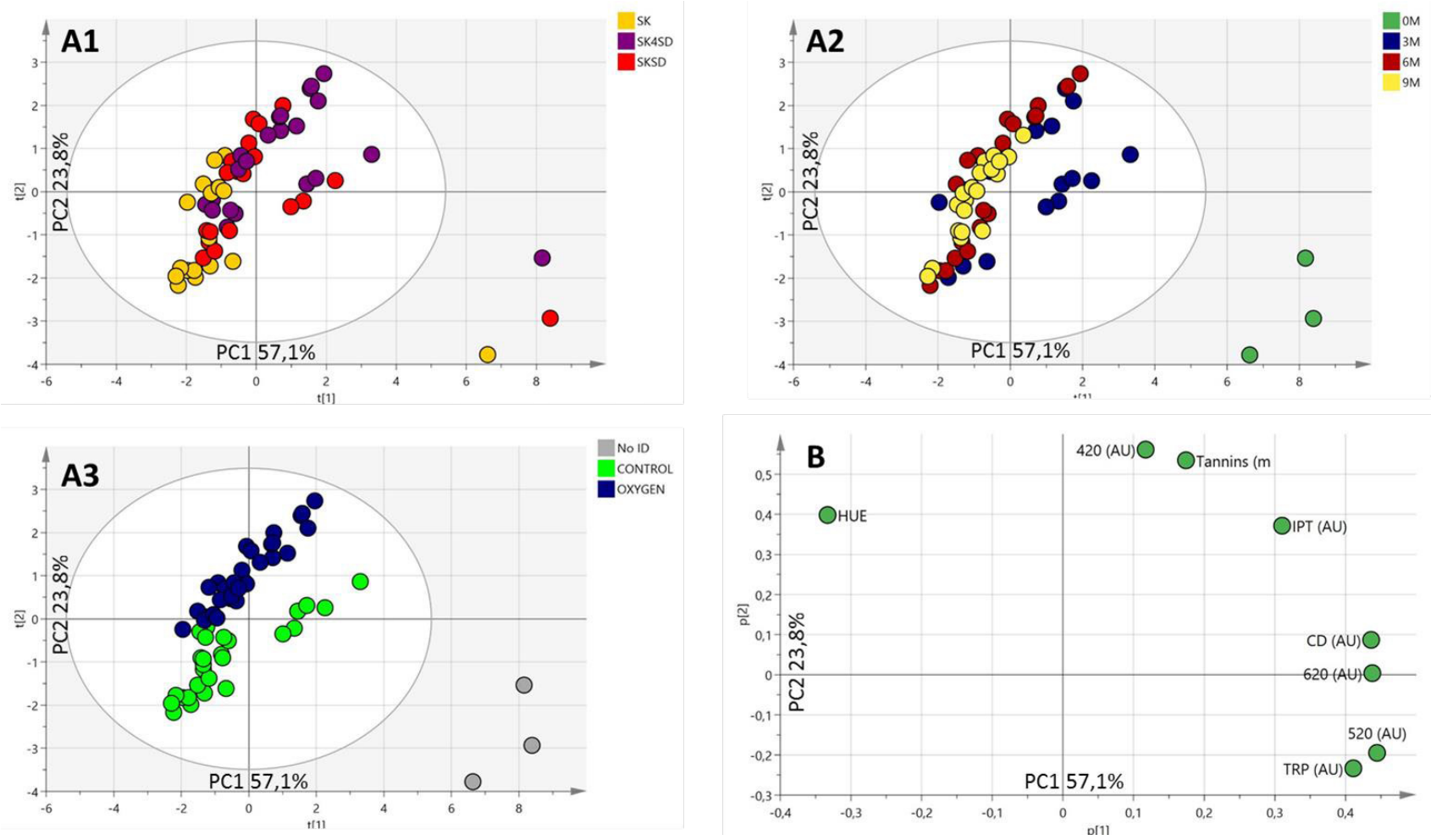

FIGURE 2

PCA score plots of the sample distribution based on the spectrophotometric data. A1) PCA score plot coloured according to the three different extracts. A2) PCA score plot coloured according to the sampling stage. A3) PCA score plot coloured according to the $\mathrm{C} / \mathrm{Ox}$ treatments. B. Loadings plot of the samples distribution based on the spectrophotometric data.

phenolic content in SK4SD treatments, especially compared to SK treatments. Over the course of time, these differences between the extracts became smaller, especially after $9 \mathrm{M}$, probably as a consequence of phenolic degradation, but also as a result of over-polymerisation reactions and subsequent precipitation of insoluble phenolic compounds. In Figure 2 A2, the samples are coloured according to the sampling stages ( $0 \mathrm{M}, 3 \mathrm{M}, 6 \mathrm{M}$ and $9 \mathrm{M})$. After $9 \mathrm{M}$, the extracts were more closely distributed along the PC1 axis (54.4\%). When the samples were coloured according to the $\mathrm{C} / \mathrm{Ox}$ treatment, the samples were distributed along the PC2 axis (21.3\%), with Ox samples being characterised by a generally higher phenolic and especially tannin concentrations (Figures 2 and 3). Contrary to the findings of Geldenhuys et al. (2012), oxygen was also found to play an important role in tannin concentrations (Figure 2 A3). However, Geldenhuys et al. (2012) applied progressive micro-oxygenation, whereas in this study a large amount of oxygen was added at a time.

A general loss of colour and reduction in phenolic levels was found over time, especially pronounced from $0 \mathrm{M}$ (Table 1) to $3 \mathrm{M}$, except for the total tannin concentration as determined by the MCP method (Figure 3 ). As an example, TRP levels decreased in all the samples during the first $3 \mathrm{M}$, especially in most of the $\mathrm{C}$ treatments. Oxygen seemed to have enhanced the polymerisation between certain compounds, thereby possibly limiting the degradation of certain red pigments. The TRP content was significantly higher in the SKSD and SK4SD Ox treatments at $3 \mathrm{M}$. From then onwards, the differences between $\mathrm{C}$ and $\mathrm{Ox}$ treatments and between the extracts became less over time.

Conversely, the tannin content showed different patterns from 0 to $3 \mathrm{M}$ within the different treatments. As illustrated in Figure 3 (values at $0 \mathrm{M}$ are specified on the $\mathrm{Y}$ axis), clear differences were found between $\mathrm{C}$ and Ox samples. While the MCP tannin levels were relatively constant from $0 \mathrm{M}$ to $3 \mathrm{M}$ in $\mathrm{C}$ samples (except for a slight increase in SKSD), an increase in the tannin concentration was observed in Ox (SKSD and SK4SD) samples during the same period. However, after $3 \mathrm{M}$, the tannin levels were only significantly higher in SK4SD-Ox samples compared to the corresponding $\mathrm{C}$ samples (Figure 3). During the following three months, the $\mathrm{C}$ treatments showed a progressive decrease in tannin concentration, except for the SK treatment (constant from $3 \mathrm{M}$ to $9 \mathrm{M}$ ), while not changing significantly up to $9 \mathrm{M}$. (Figure 3). On the other hand, the Ox treatments' tannin levels increased (SK and SKSD) or remained stable (SK4SD) up to $6 \mathrm{M}$ of storage, which might also explain the different oxygen consumption rates observed for the second oxidation step after $3 \mathrm{M}$ of storage. From then, all the Ox extracts experienced a general decrease in tannin concentration towards the last sampling stage (9M). This decrease can possibly be explained by the formation of larger and/or more unstable polymers which are no longer soluble in the hydroalcoholic solution. Thus, the oxygen had an impact on the tannin polymerisation reactions, and likely the reactivity of the polymerisation reaction products towards methylcellulose (Figure 3). The significant role of oxygen in tannin polymerisation has been widely documented in 
Treatment*Ratio*TIME; LS Means

Current effect: $F(4,10)=4.3221, p=.02754$

Vertical bars denote 0.95 confidence intervals

Include condition: TIME<>"OM"

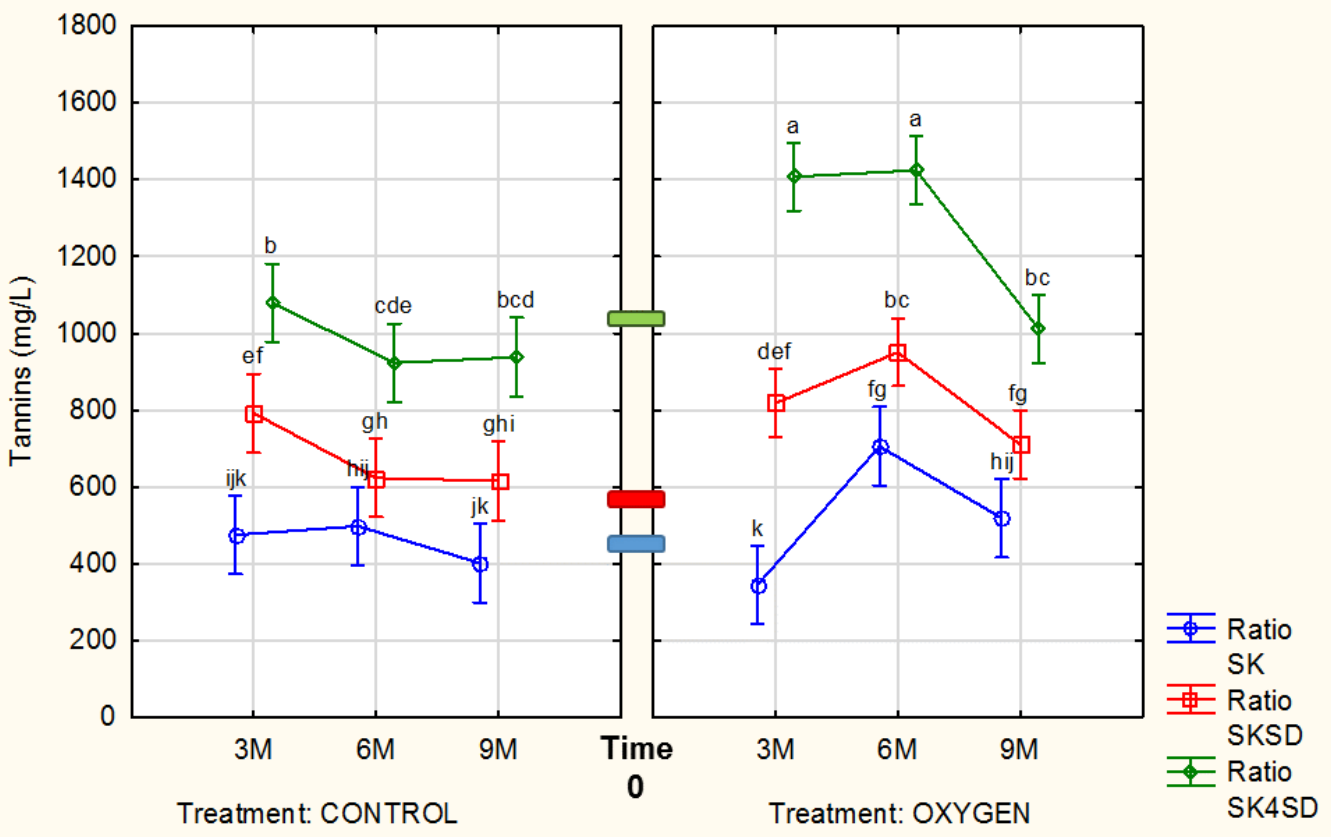

FIGURE 3

Evolution of the MCP tannin levels (mg/L) of all extracts (SK, SKSD and SK4SD) over time. Values at time $0(0 \mathrm{M})$ are marked on the Y axis. The different letters indicate significant differences (ANOVA, $\mathrm{p}<0.05$ ) between the A/T ratios, oxygen treatments and storage times.

literature (Singleton, 1987; Castellari et al., 2000; Atanasova et al., 2002; Waterhouse \& Laurie, 2006; Gambuti et al., 2013; Quaglieri et al., 2017).

Oxygen also influenced the evolution of the amount of TRP in the extracts. In the presence of oxygen, higher phenolic levels might compete for reaction with oxygen, favouring specific polymerisation reactions. Thus, the higher pigment content can be explained by the depletion of oxygen as a consequence of the reaction of other phenolic compounds with oxygen, instead of the anthocyanins/pigments.

\section{HPLC data for individual phenolics}

Results obtained for the RP-LC analysis of selected individual phenolic concentrations are summarised in Tables 1 and 2. The different extracts, the presence/absence of oxygen and storage time played a role in affecting the phenolic composition of the treatments. Large differences in gallic acid concentrations were found between the three extracts. Higher amounts of seeds led to an obvious increase in gallic acid content (Table 1 ) at $0 \mathrm{M}$. From time $0 \mathrm{M}$ to $3 \mathrm{M}$, a consistent decrease in the gallic acid concentration was observed for all samples, possibly linked to the formation of new polymeric forms (especially in SK4SD), precipitation or degradation reactions. The hypothetical interaction between gallic acid quinones and flavonol units has recently been reported (Mouls \& Fulcrand, 2015). The concentration of polymeric phenols was also significantly higher in SKSD and SK4SD compared to SK samples (Table 2). These differences between the extracts remained over time. Over the storage time investigated (especially from $6 \mathrm{M}$ ), the polymeric phenol content was generally higher in Ox treatments. Therefore, the presence and reactivity of seed derived compounds and oxygen may influence polymerisation reactions.

Higher total flavonol contents were found in the Ox samples; however, the total hydroxycinnamic acid concentrations were higher in the $\mathrm{C}$ samples. Unexpectedly, the total hydroxycinnamic acid content seemed to slightly increase over time (Table 2), although in some cases not significantly. Literature reports a general decrease of hydroxycinnamic acid concentrations during storage (García-Falcón et al., 2007). However, an increase of certain hydroxycinnamic acids has also been observed (GarcíaFalcón et al., 2007; Arapitsas et al., 2014), possibly as a result of copigment degradation expected to occur over time (Bimpilas et al., 2016).

Likewise, a large decrease was observed in the anthocyanin concentrations of all treatments from $0 \mathrm{M}$ (Table 1) to $3 \mathrm{M}$ (Table 2). The larger decrease in anthocyanin levels observed in the $\mathrm{C}$ treatments was not associated with the formation of higher polymeric pigments (Table 2). Nevertheless, the HPLC results confirmed the idea of certain oxidative reactions between phenols being favoured in the presence of oxygen. The oxidation of ethanol and tartaric acid could possibly have led to the formation of ethyl bridged structures between tannins moieties, thereby leading to lower reactivity of free anthocyanins. This may explain the higher concentration of monomeric anthocyanins 


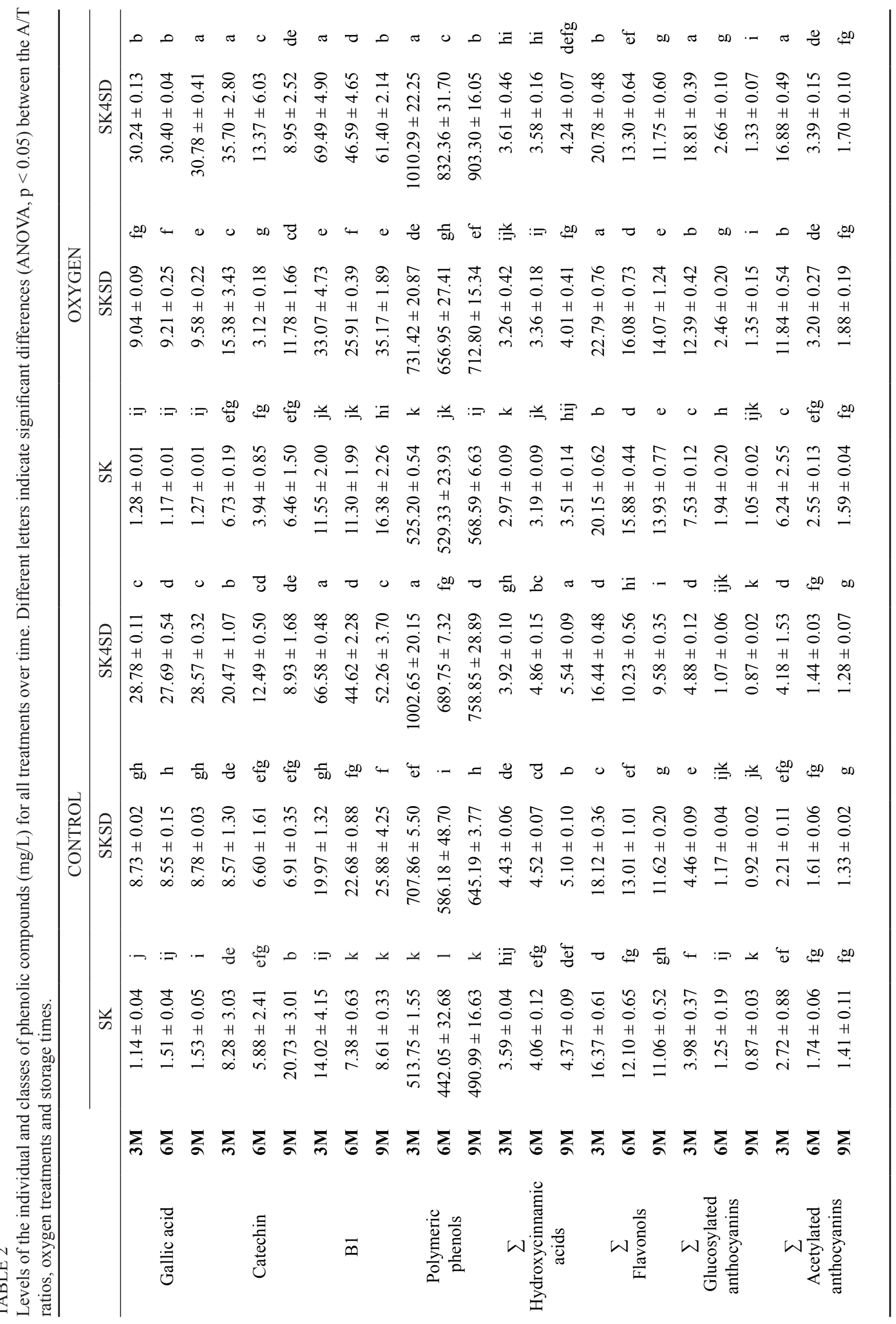




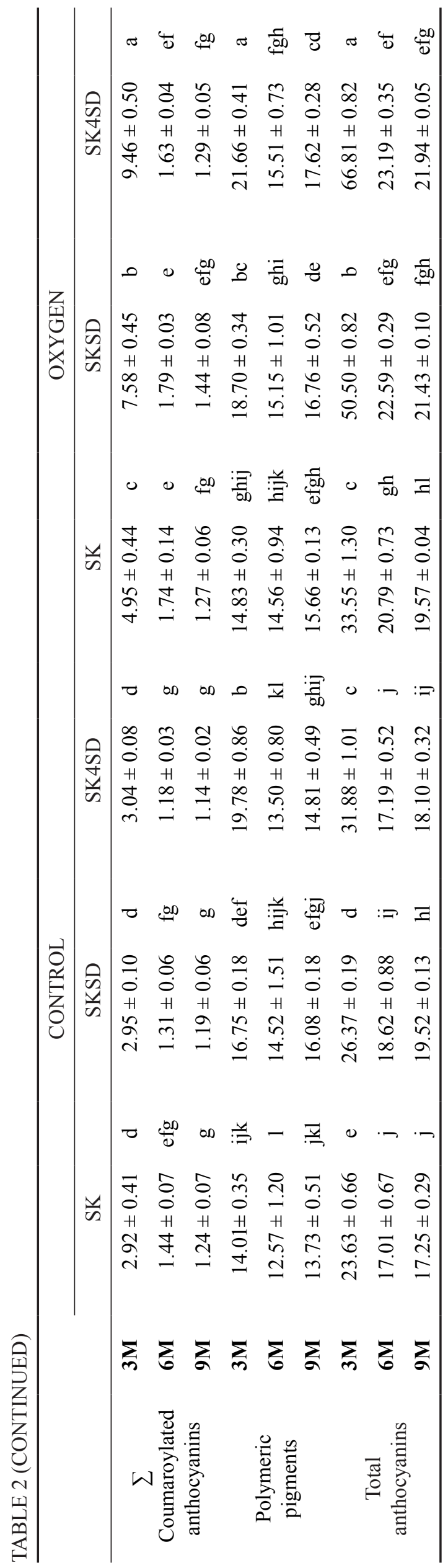

found after $3 \mathrm{M}$, in the treatments where higher levels of seeds were present and oxygen added. Supporting this, after $3 \mathrm{M}$ of storage, SK and SKSD samples showed a greater decrease in glucosylated, acetylated and coumaroylated anthocyanins in the absence of oxygen. On the other hand, SK4SD samples initially had higher concentration of polymeric pigments, thereby influencing the polymerisation reactions. These differences between the extracts in the concentrations of polymeric pigments, for both $\mathrm{C}$ and $\mathrm{Ox}$ samples, were also found at $3 \mathrm{M}$, but disappeared after $6 \mathrm{M}$ of storage. In the interpretation of these results, we cannot discard the possibility that certain polymeric pigments are not detected by the RP-HPLC method. Nevertheless, after $6 \mathrm{M}$, all treatments experienced anthocyanin degradation and differences between treatments became smaller. The decrease in anthocyanins showed different rates among the different extracts. This delay may be linked to the excess of seed phenolics, with a higher reactivity in the presence of oxygen, and the exposure to several severe oxidations. These repeated oxidations could lead to over polymerisation, forming phenolic derived compounds not stable in solution, therefore precipitating. This anthocyanin degradation over time has been widely reported in red wines, and is at least partly a consequence of the formation of pigmented polymers (Somers, 1971; Somers \& Evans, 1979; Pérez-Magariño \& González-SanJosé, 2004; Arapitsas et al., 2014; Quaglieri et al., 2017). Also, the loss of anthocyanin derived forms over time was previously reported to be lower in oxygenated wines (Atanasova et al., 2002).

\section{CONCLUSIONS}

To date, a number of studies have focused on the impact of seed addition or removal on the colour, phenolic profile and sensory properties of wines (Meyer \& Hernandez, 1970; Canals et al., 2008; Lee et al., 2008; Guaita et al., 2017), but there is a lack of information on the evolution of these wine parameters with age, as well as on the role of oxygen in this process. The main goal of this study was to assess the impact of oxygen addition on the phenolic composition of WL extracts containing three different defined $\mathrm{A} / \mathrm{T}$ ratios. The extract composition seemed to play a greater role than the oxygen in phenolic evolution. Our results highlight the importance of the initial $\mathrm{A} / \mathrm{T}$ ratio and of the nature of these respective compound classes on the polymerisation reactions occurring during initial stages of ageing. The higher the concentration of phenols in the solution, the greater the number of molecules susceptible to polymerise, and therefore the greater the competition between these substrates. In this context, seed derived phenols showed a high reactivity to form larger polymeric structures, both in the absence or presence of oxygen. Nevertheless, as a consequence of the oxidative process, excessive seed content may enhance the polymerisation reactions between proanthocyanidins, and thereby favour remaining of free monomeric anthocyanins in solution. The increase in polymeric phenols (Table 2), together with the higher levels of TRP and of monomeric anthocyanins (total glucosylated, acetylated and coumaroylated forms) in the SK4SD-Ox samples after $3 \mathrm{M}$ of storage (Table 2), support this idea. Further research needs to investigate not only the impact of 
different phenolic ratios on the phenolic stability, but also the polymerisation reactions in the presence of different grape polysaccharides and protein proportions.

\section{LITERATURE CITED}

Adams, D.O., 2006. Phenolics and ripening in grape berries. Am. J. Enol. Vitic. 57, 249-256.

Arapitsas, P., Corte, A., Della., Gika, H., Narduzzi, L., Mattivi, F. \& Theodoridis, G., 2016. Studying the effect of storage conditions on the metabolite content of red wine using HILIC LC-MS based metabolomics. Food Chem. 197, 1331-1340.

Arapitsas, P., Scholz, M., Vrhovsek, U., Blasi, S., Biondi, A., Masuero, D., Perenzoni, D., Rigo, A. \& Mattivi, F., 2012. A Metabolomic Approach to the Study of Wine Micro- Oxygenation. PLoS ONE 7, 1-11.

Arapitsas, P., Speri, G., Angeli, A., Perenzoni, D. \& Mattivi, F., 2014. The influence of storage on the "chemical age" of red wines. Metabolomics $10,816-832$.

Atanasova, V., Fulcrand, H., Cheynier, V. \& Moutounet, M., 2002. Effect of oxygenation on polyphenol changes occurring in the course of winemaking. Analytica Chimica Acta. 458, 15-27.

Bimpilas, A., Panagopoulou, M., Tsimogiannis, D. \& Oreopoulou, V., 2016. Anthocyanin copigmentation and color of wine: The effect of naturally obtained hydroxycinnamic acids as cofactors. Food Chem. 197, 39-46.

Bimpilas, A., Tsimogiannis, D., Balta-Brouma, K., Lymperopoulou, T. \& Oreopoulou, V., 2015. Evolution of phenolic compounds and metal content of wine during alcoholic fermentation and storage. Food Chem. 178, 164171.

Bindon, K.A., Smith, P.A. \& Kennedy, J.A., 2010. Interaction between Grape-Derived Proanthocyanidins and Cell Wall Material. Effect on Proanthocyanidin Composition and Molecular Mass. J. Agric. Food Chem. $58,2520-2528$.

Boulton, R., 2001. The copigmentation of anthocyanins and its role in the color of red wine: a critical review. Am. J. Enol. Vitic. 52, 67-87.

Canals, R., Llaudy, C., Miquel, J. \& Fernando, C., 2008. Influence of the elimination and addition of seeds on the colour, phenolic composition and astringency of red wine. Am. J. Enol. Vitic. 226, 1183-1190.

Carrascón, V., Vallverdú-Queralt, A., Meudec, E., Sommerer, N., Fernandez-Zurbano, P. \& Ferreira, V., 2018. The kinetics of oxygen and SO2 consumption by red wines. What do they tell about oxidation mechanisms and about changes in wine composition? Food Chem. 241, 206-214.

Casassa, L.F., 2017. Flavonoid Phenolics in Red Winemaking. Phenolic Compounds - Natural Sources, Importance and Applications

Castellari, M., Matricardi, L., Arfelli, G., Galassi, S. \& Amati, A., 2000. Level of single bioactive phenolics in red wine as a function of the oxygen supplied during storage. Food Chem. 69, 61-67.

Cheynier, V., Salas, E., Souquet, J., Sarni-Manchado, P. \& Fulcrand, H., 2006. Structure and Properties of Wine Pigments and Tannins. Am. J. Enol. Vitic. 3, 298-305.

Coetzee, C., Van Wyngaard, E., Šuklje, K., Silva Ferreira, A.C. \& Du Toit, W.J., 2016. Chemical and Sensory Study on the Evolution of Aromatic and Nonaromatic Compounds during the Progressive Oxidative Storage of a Sauvignon blanc Wine. J. Agric. Food Chem. 64, 7979-7993.

Dallas, C., Ricardo-da-Silva, J.M. \& Laureano, O., 1996. Interactions of Oligomeric Procyanidins in Model Wine Solutions Containing Malvidin-3Glucoside and Acetaldehyde. J. Sci. Food Agric. 70, 493-500.
Danilewicz, J.C., 2007. Interaction of sulfur dioxide, polyphenols, and oxygen in a wine-model system: Central role of iron and copper. Am. J. Enol. Vitic. 58, 53-60.

Es-Safi, N.E., Fulcrand, H., Cheynier, V. \& Moutounet, M., 1999. Studies on the acetaldehyde-induced condensation of (-)-epicatechin and malvidin 3-O-glucoside in a model solution system. J. Agric. Food Chem. 47, 20962102 .

Fulcrand, H., Cameira dos Santos, P.J., Sarni-Manchado, P., Cheynier, V. \& Favre-Bonvin, J., 1996. Structure of new anthocyanin-derived wine pigments. J. Chem. Soc. $69,60$.

Gambuti, A., Rinaldi, A., Ugliano, M. \& Moio, L., 2013. Evolution of Phenolic Compounds and Astringency during Aging of Red Wine: Effect of Oxygen Exposure before and after Bottling. J. Agric. Food Chem. 61, $1618-1627$.

García-Falcón, M.S., Pérez-Lamela, C., Martínez-Carballo, E. \& SimalGándara, J., 2007. Determination of phenolic compounds in wines: Influence of bottle storage of young red wines on their evolution. Food Chem. 105, 248-259.

Garrido-Bañuelos, G., Buica, A., Schückel, J., Zietsman, A.J.J., Willats, W.G.T., Moore, J.P. \& Du Toit, W.J., 2019. Investigating the relationship between grape cell wall polysaccharide composition and the extractability of phenolic compounds into Shiraz wines. Part I: Vintage and ripeness effects. Food Chem. 278, 36-46.

Geldenhuys, L., Oberholster, A. \& Du Toit, W., 2012. Monitoring the Effect of Micro-oxygenation before Malolactic Fermentation on South African Pinotage Red Wine with Different Colour and Phenolic Analyses. SA J. Enol. Vitic. 33, 150-160.

González-Manzano, S., Rivas-Gonzalo, J.C. \& Santos-Buelga, C., 2004. Extraction of flavan-3-ols from grape seed and skin into wine using simulated maceration. Analytica Chimica Acta. 513, 283-289.

González-Manzano, S., Santos-Buelga, C., Pérez-Alonso, J.J., RivasGonzalo, J.C. \& Escribano-Bailón, M.T., 2006. Characterization of the mean degree of polymerization of proanthocyanidins in red wines using Liquid Chromatography-Mass Spectrometry (LC-MS). J. Agric. Food Chem. 54, 4326-4332.

Guaita, M., Petrozziello, M., Panero, L., Tsolakis, C., Motta, S. \& Bosso, A., 2017. Influence of early seeds removal on the physicochemical, polyphenolic, aromatic and sensory characteristics of red wines from Gaglioppo cv. Eur. Food Res. Technol. 243, 1311-1322.

He, F., Liang, N., Mu, L., Pan, Q., Wang, J., Reeves, M.J. \& Duan, C., 2012a. Anthocyanins and Their Variation in Red Wines I. Monomeric Anthocyanins and Their Color Expression. Molecules. 17, 1571-1601.

He, F., Liang, N., Mu, L., Pan, Q., Wang, J., Reeves, M.J. \& Duan, C., 2012b. Anthocyanins and Their Variation in Red Wines II. Anthocyanin Derived Pigments and Their Color Evolution. Molecules 17, 1483-1519.

Kennedy, J.A., Saucier, C. \& Glories, Y., 2006. Grape and Wine Phenolics: History and Perspective. Am. J. Enol. Vitic. 3, 20-21.

Lee, J., Kennedy, J.A., Devlin, C., Redhead, M. \& Rennaker, C., 2008. Effect of early seed removal during fermentation on proanthocyanidin extraction in red wine: A commercial production example. Food Chem. $107,1270-1273$.

Mattivi, F., Vrhovsek, U., Masuero, D. \& Trainotti, D., 2009. Differences in the amount and structure of extractable skin and seed tannins amongst red grape varieties. Aust. J. Grape Wine Res. 15, 27-35.

McRae, J.M., Day, M.P., Bindon, K.A., Kassara, S., Schmidt, S.A., Schulkin, A., Kolouchova, R. \& Smith, P.A., 2015. Effect of early oxygen exposure on red wine colour and tannins. Tetrahedron 71, 3131-3137.

Meyer, B.J. \& Hernandez, R., 1970. Seed Tannin Extraction in Cabernet Sauvignon. Am. J. Enol. Vitic. 21, 184-188. 
Monagas, M., Gómez-Cordovés, C. \& Bartolomé, B., 2006. Evolution of the phenolic content of red wines from Vitis vinifera L. during ageing in bottle. Food Chem. 95, 405-412.

Mouls, L. \& Fulcrand, H., 2015. Identification of new oxidation markers of grape-condensed tannins by UPLC e MS analysis after chemical depolymerization. Tetrahedron 71, 3012-3019.

Pascual, O., González-Royo, E., Gil, M., Gómez-Alonso, S., GarcíaRomero, E., Canals, J.M., Hermosín-Gutiérrez, I. \& Zamora, F., 2016 Influence of Grape Seeds and Stems on Wine Composition and Astringency. J. Agric. Food Chem. 64, 6555-6566.

Pascual, O., Vignault, A., Gombau, J., Navarro, M., Gómez-Alonso, S., García-Romero, E., Canals, J.M., Hermosín-Gutiérrez, I., Teissedre, P.L. \& Zamora, F., 2017. Oxygen consumption rates by different oenological tannins in a model wine solution. Food Chem. 234, 26-32.

Peleg, H., Gacon, K., Schlich, P. \& Noble, A.C., 1999. Bitterness and astringency of flavan-3-ol monomers, dimers and trimers. J. Sci. Food and Agric. 79, 1123-1128.

Pérez-Magariño, S. \& González-SanJosé, M.L., 2004. Evolution of flavanols, anthocyanins, and their derivatives during the aging of red wines elaborated from grapes harvested at different stages of ripening. J. Agric. Food Chem. 52, 1181-1189.

Peyrot Des Gachons, C. \& Kennedy, J.A., 2003. Direct Method for Determining Seed and Skin Proanthocyanidin Extraction into Red Wine. J. Sci. Food Agric. 51, 5877-5881.

Picariello, L., Gambuti, A., Picariello, B. \& Moio, L., 2017. Evolution of pigments, tannins and acetaldehyde during forced oxidation of red wine: Effect of tannins addition. LWT - Food Sci. Technol. 77, 370-375.

Quaglieri, C., Jourdes, M., Waffo-Teguo, P. \& Teissedre, P.L., 2017. Updated knowledge about pyranoanthocyanins: Impact of oxygen on their contents, and contribution in the winemaking process to overall wine color. Trends Food Sci. Technol. 67, 139-149.

Ribéreau-Gayon, P., Glories, Y., Maujean, A. \& Dubourdieu, D., 2006 (Vol. 2). Handbook of Enology. The chemistry of wine. Stabilization and treatments. John Wiley \& Sons, LTD,

Sarneckis, C.J., Dambergs, R.G., Jones, P., Mercurio, M., Herderich, M.J. \& Smith, P.A., 2006. Quantification of condensed tannins by precipitation with methyl cellulose: Development and validation of an optimised tool for grape and wine analysis. Aust. J. Grape Wine Res. 12, 39-49.

Saucier, C., Bourgeois, G., Vitry, C., Roux, D. \& Glories, Y., 1997. Characterization of $(+)$-Catechin-Acetaldehyde Polymers: A Model for Colloidal State of Wine Polyphenols. J. Agric. Food Chem. 45, 1045-1049.

Singleton, V.L., 1987. Oxygen with phenols and related reactions in musts, wines, and model systems: observations and practical implications. Am. J. Enol. Vitic. 38, 69-77.
Singleton, V.L. \& Trousdale, E.K., 1992. Anthocyanin-Tannin Interactions Explaining differences in polymeric phenols between white and red wines. Am. J. Enol. Vitic. 43, 63-70.

Somers, T.C., 1971. The Polymeric Nature of Wine Pigments. Phytochem. $10,2175-2186$

Somers, T.C. \& Evans, M.E., 1974. Wine Quality: Correlations with Colour Density and Anthocyanin Equilibria in a Group of Young Red Wines. J. Agric. Food Chem. 25, 1369-1379.

Somers, T.C. \& Evans, M.E., 1979. Grape pigment phenomena: Interpretation of major colour losses during vinification. J. Sci. Food Agric. $30,623-633$.

Souquet, J.M., Cheynier, V., Brossaud, F. \& Moutounet, M., 1996. Polymeric proanthocyanidins from grape skins. Phytochem. 43, 509-512.

Sparrow, A.M., Dambergs, R.G., Bindon, K.A., Smith, P.A. \& Close, D.C., 2015. Interaction of Grape Skin, Seed, and Pulp Tissues on Tannin and Anthocyanin Extraction in Pinot noir Wines. Am. J. Enol. Vitic., 1-27.

Springer, L.F., Chen, L.A., Stahlecker, A.C., Cousins, P. \& Sacks, G.L., 2016. Relationship of Soluble Grape-Derived Proteins to Condensed Tannin Extractability during Red Wine Fermentation. J. Agric. Food Chem. 64, 8191-8199.

Timberlake, C.F. \& Bridle, P., 1977. Anthocyanins: Colour Augmentation with Catechin and Acetaldehyde. J. Sci. Food Agric. 28, 539-544.

Du Toit, W.J., Marais, J., Pretorius, I.S. \& Du Toit, M., 2006. Oxygen in must and wine: A review. SA J. Enol. Vitic. 27, 76-94.

Versari, A., Du Toit, W. \& Parpinello, G.P., 2013. Oenological tannins: A review. Aust. J. Grape Wine Res. 19, 1-10.

Vignault, A., González-Centeno, M.R., Pascual, O., Gombau, J., Jourdes, M., Moine, V., Iturmendi, N., Canals, J.M., Zamora, F. \& Teissedre, P.L., 2018. Chemical characterization, antioxidant properties and oxygen consumption rate of 36 commercial oenological tannins in a model wine solution. Food Chem. 268, 210-219.

Waterhouse, A.L. \& Laurie, V.F., 2006. Oxidation of wine phenolics: A critical evaluation and hypotheses. Am. J. Enol. Vitic. 57, 306-313.

Wirth, J., Morel-Salmi, C., Souquet, J.M., Dieval, J.B., Aagaard, O., Vidal, S., Fulcrand, H. \& Cheynier, V., 2010. The impact of oxygen exposure before and after bottling on the polyphenolic composition of red wines. Food Chem. 123, 107-116.

Yacco, R.S., Watrelot, A.A. \& Kennedy, J.A., 2016. Red Wine Tannin Structure-Activity Relationships during Fermentation and Maceration. J. Agric. Food Chem. 64, 860-869. 